\title{
sciendo
}

\section{DEVELOPMENT OF A SCALE FOR MEASURING THE LEARNER AUTONOMY OF DISTANCE EDUCATION STUDENTS}

\author{
EvanthiaBei[evib13@yahoo.gr], Ilias Mavroidis_imav@tee.gr], Yiannis Giossos [xayiannis@gmail.com], \\ Hellenic Open University, Aristotelous 18, 26335, Patras,Greece, [https://wmw.eap.gr/el/], Greece
}

\begin{abstract}
The purpose of this study was to develop a valid and reliable psychometric scale to measure the perceived autonomy of postgraduate students in the Hellenic Open University and similar distance education environments. Two dimensions of autonomy, namely personal and educational, were revealed from the literature review and the preliminary study. For the evaluation of each dimension, two subscales were developed. Following two pilot studies, the initial item pool led to the development of a 25 -items questionnaire, which was then administered to a sample of 239 postgraduate students. The exploratory factor analysis revealed two factors for the personal autonomy subscale, with 7 items in total, and two factors for the educational autonomy subscale, with 9 items in total. The Cronbach's alpha coefficient ranged between .623 and .717. A statistically significant gender difference was found only for the personal autonomy subscale and, more specifically, for the factor 'managing difficulties', where female respondents received a lower score than males.
\end{abstract}

\section{Abstract in Greek}

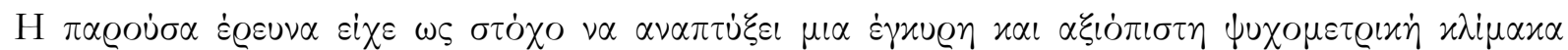

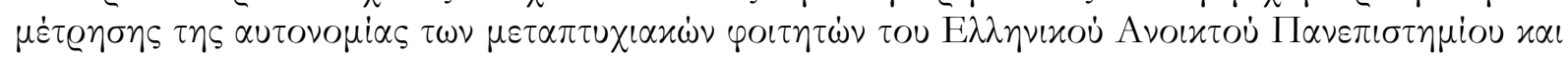

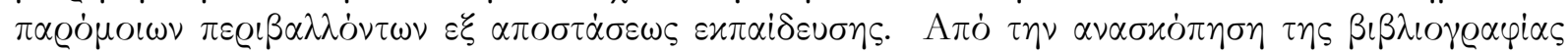

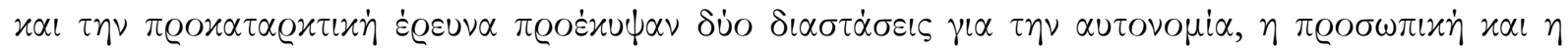

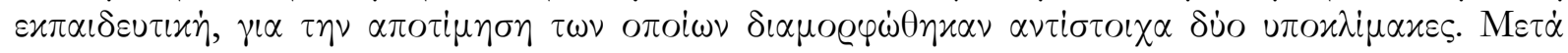

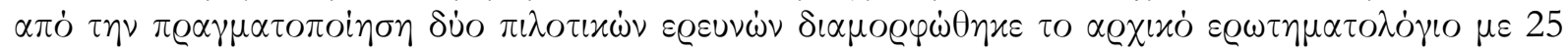

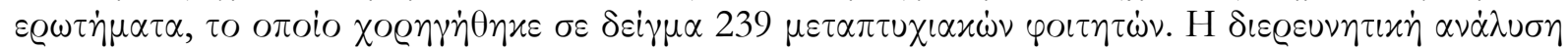

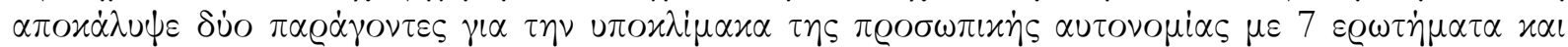

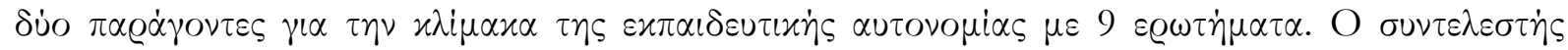

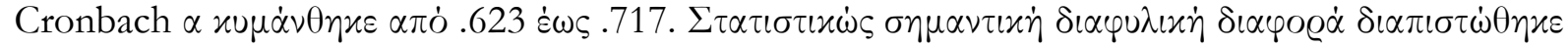

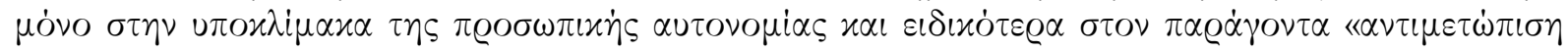

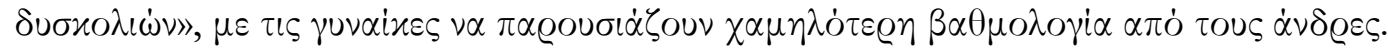

Key-words: Distance education, autonomy scale, personal autonomy, educational autonomy

\section{Introduction}

Distance education, a flexible educational method with specific demands, motivates the learner (pupil and/or student) to exert control over his/her own learning (Andrade \& Bunker, 2009; Lionarakis, 2001). On this basis, learner's autonomy is not only required, but also facilitated by the very nature of a distance education environment; consequently, it reveals itself as a main factor for a successful learning process (Furnborough, 2012; Peters, 2000; Santos \& Camara, 2010). This led many of the theoreticians of education to study and critically analyse the notion of learner autonomy in the context of distance education (Anderson, 2007; Brockett \& Hiemstra, 1991; Fotiadou, Angelaki, \& Mavroidis, 2017; Keegan, 1996; Little, 2004). Moore (1993), while developing the theory of transactional distance, defined autonomy as a perceived, experiential 
learner situation, during which learners take the responsibility of their own learning exerting control over all the phases of the educational process. On the other hand, Peters notes that for learners to be autonomous they have to be "meta-cognitively, motivationally and behaviorally active participants in their own learning" (Peters, 1998; p.48).

Some researchers describe autonomous learning as an ability to independently acquire knowledge or skills (Chene, 1983), while others as a psychological characteristic of an individual to independently direct his/her learning (Merriam \& Caffarella, 1999). Oxford (2008) suggests that in an autonomous learning environment, the learner makes decisions involving both planning and implementation, while when the level of learner autonomy is lower, learners make considerably fewer decisions linked to implementation. According to Little (1995) and Moore $(1993$; 2007), learners' autonomy does not mean that they do not need the tutor's support; on the contrary, both researchers emphasize the importance of the tutor's supportive, encouraging and motivating role.

\section{Literature review}

According to Garrison (2003), independence and autonomy were initially associated with the industrial model of distance education. Moore (1993) integrated autonomy with distance teaching and linked it with the concepts of structure and dialogue. Moore's theory of transactional distance recognized the importance of dialogue between and among tutors and learners in an educational process. Through the autonomy dimension and self-directed learning, transactional distance went beyond the concept of control by raising important cognitive issues; in Moore's theory of transactional distance, autonomy appears to view the transaction from the learner's perspective, related also to the degree of control the learner has over preparation, execution, and evaluation of his/her learning (Garrison, 2003). Peters (1998) also challenged the industrial approach to distance education, asking for greater pedagogical imagination and for the treatment of students not as objects but as subjects of the teaching process (Garrison, 2003). He therefore linked distance education with learner autonomy, as his approach transfers considerable trust and responsibility to the learner. As noted above, according to Peters (1998), autonomous learners are "meta-cognitively, motivationally and behaviorally active participants in their own learning". Garrison (2003) suggests that this approach has common core perceptions with the self-directed learning model put forward by Garrison (1997), of which monitoring, motivation, and management are core elements.

In order to measure learner autonomy, many scales have been presented in the relevant literature. These include Guglielmino's SDLR scale (1977), Fisher, King, and Tague's SDLRS-40 scale (2001), Walker and Fraser's DELES-39 scale (2005), Becker and van Assen's ACS-30 scale (2006) and, most recently, Macaskill and Taylor's ALS-12 scale (2010). Problems with the construct validity had been reported from researchers for Guglielmino's scale and the recommendation was to discontinue its use (Candy, 1991; Field, 1989; Straka \& Hinz, 1996). According to Macaskill and Taylor (2010), Fisher, King, and Tague's SDLRS-40 scale is fairly long and developed for a specific group of nursing students. The DELES-39 scale is developed to assess in general the learning in distance education environments, with only 5 items related to learner autonomy (Biggs, 2006). The most recently constructed scales for measuring learner autonomy (van Assen's ACS-30 and Macaskill and Taylor's ALS-12) were not purely developed in distance education environments.

Examination of autonomy in the context of the Hellenic Open University (HOU) has been limited. Only the studies of Fotiadou, Angelaki, and Mavroidis (2017) and of Giossos, Koutsouba, and Mavroidis (2016) have measured the autonomy of the postgraduate students of HOU, both using the Becker and Van Assen (2006) scale. However, the HOU applies a unique, 
model of distance education, which combines five optional and face-to-face counselling group sessions, as well as distance means of communication and learning tools (Fotiadou, Angelaki, \& Mavroidis, 2015). As it has been remarked by Lemone (2005), learner autonomy changes according to the conditions that pertain to the cultural and educational environment of its development. Additionally, there is a discussion in the literature concerning the potential validation problems that emerge, including those customarily associated with instrument development, when using a psychometric scale developed in a different cultural and educational context from that of the case study (Sawilowsky, 2000; Sherril \& O'Connor, 1999; Yun \& Urlich, 2002). In other words, it is "safer" and more efficient to use an instrument/scale, which has been developed within the learning environment of the particular examined population or of a very similar one. In this specific case, in order to ensure the validity in measuring autonomy among HOU postgraduate students, an instrument/scale is developed focusing on the learning environment of the HOU. Such a new, customized scale could be used not only in the context of HOU but also on similar learning environments.

A dual theoretical approach was adopted for the development of the autonomy scales. In particular, (a) Moore's theory (1993), which faced autonomy as an experiential, perceived situation, and (b) Garrison's approach (2000), which suggested two discrete dimensions of autonomy. The first dimension is related to the psychological, personal characteristics of the learners (psychological or personal dimension of autonomy) and the second one is related to the educational programme itself (educational dimension of autonomy). The aforementioned theoretical assumptions led to the development of the two subscales: one for evaluating personal autonomy and one for evaluating educational autonomy.

To this end, the development of a new scale could also assist in clarifying one further point: as Garrison (2003) has pointed out, Moore treated autonomy as a personality characteristic associated with self-directedness and personal responsibility. There is a need though to clarify whether Moore's concept of autonomy concerns educational or psychological/personal autonomy. The process for the development of the scale presented in this study can be also used to provide some insight on whether these two dimensions of autonomy exist separately.

Following the above, the purpose of the present study is to develop a scale for measuring the learner's autonomy of HOU postgraduate students, while providing psychometric evidence of reliability and validity of the interpretation of the scores derived from this scale. The specific study questions are the following: (a) what would be the items that such a scale could include, (b) what would be the validity of the scale, and (c) what would be the reliability of the scale. At the same time, and through the development and evaluation of the items of the scale, the study aims to provide insight to the main factors related to the autonomy of learners in the Hellenic Open University.

The validity of a measurement scale alludes to the extent to which the scale measures what it should supposedly measure (Thomas \& Nelson, 1996). More specifically, the American Union of Psychologists, the American Union of Educational Research and the National (American) Council of Measurements in Education refer to a series of criteria used in order to support the validity of a measurement/scale/test (Gall, Borg, \& Gall, 2014). These criteria could be classified in: (a) those which refer to the extent to which the test items are a sample of a universe in which the investigator is interested, namely content validity (Cronbach \& Meehl, 1955), (b) those which refer to the degree to which a test can be interpreted as a measure of some attribute or quality which is not "operationally defined" (Cronbach \& Meehl, 1955), namely construct validity, and (c) those which refer to the extent to which the test constitutes an independent measure criterion on the same attributes and computes a correlation, namely criterion validity (Cronbach \& Meehl, 1955). In the present study the construct validity is thoroughly investigated. 
Finally, the reliability of a measurement scale refers to the stability that the scale demonstrates in consecutive tests and is distinguished in: (a) test-retest reliability, (b) alternate form reliability or parallel form reliability, (c) split-half reliability, and (d) internal consistency reliability (Gall, Borg, \& Gall, 2014). Internal consistency reliability of a scale is a function of the number of items and their correlation; Cronbach's alpha is the coefficient commonly used to estimate it. In the present study the internal consistency reliability is investigated.

\section{Method}

The process of developing the learner autonomy scale comprised of two phases. In the first phase, the items of the scale were developed and in the second phase these items were evaluated.

\section{Development of the items of the scale}

In the first phase, an extensive literature review of the theory of autonomy and a review of the existing relevant scales were performed. Then, an interview with four HOU postgraduate students ( 2 men and 2 women), using open ended questions, were conducted.

The purpose was to identify a conceptual framework for learner autonomy and to identify which items were the most important to represent the instrument's dimensions. On the basis of the literature review and of the interviews, an initial scale was developed.

\section{Evaluation of the items of the scale}

In the second phase, the above questionnaire was initially reviewed by two HOU postgraduate students in order to evaluate face validity and by three academics of distance education in order to evaluate sufficiency, interest and clarity of the items on the scale.

Following this, a pilot study took place. During this pilot study, the scale was administered twice, first on a random sample of 62 postgraduate students and then on a random sample of another 22 postgraduate students, in order to ensure its clarity.

Finally, the scale was administered on a random sample of 239 postgraduate students of the HOU who were attending different course modules during the academic year 2015-16 to ensure its construct validity.

To examine the construct validity of the subscales-questionnaires, the subsequent four preliminary tests related to the suitability of the scale and the sampling adequacy for factor analysis were performed: (a) the Pearson's $r$ linear correlation coefficient, (b) the Bartlett's test of sphericity to test the variables' independence, (c) the Kaiser-Meyer-Olkin measure of sampling adequacy, and (d) the discriminant of table $\mathrm{R}$ to test the multicollinearity. As for the factorability itself, an exploratory factor analysis was performed using the technique of principal axis factoring with direct oblimin. The identification of the number of factors was based on the screen plot.

To examine the internal consistency and the reliability of each subscale (personal and educational) regarding the homogeneity of the responses to the items, the Cronbach's alpha coefficient was used. Finally, the multivariable analysis of variance (MANOVA) was conducted to test the potential gender differences in the mean scores of men and women on the Personal Autonomy Scale (PAS) and the Educational Autonomy Scale (EAS). 


\section{Results and main findings}

\section{Development of the scale}

As noted above, the theoretical assumptions led to the development of the two subscales, one for evaluating personal autonomy and one for evaluating educational autonomy. The critical analysis of the notion of autonomy gave rise to a number of items, which in turn composed the scale. More specifically, as far as personal autonomy is concerned, items emerged regarding the assumption of personal responsibility, personal control, active involvement, self-awareness, internal motivation, insistence, etc. Educational autonomy included items relevant to the awareness of the learning needs, the organization, monitoring and assessment of the learning process, the extent to which students expect their tutor to transfer the control of the educational procedure to them, etc. The items of the scale were enriched taking into consideration the analysis of the HOU educational framework as well as other relevant scales described in the literature (e.g. Bekker \& van Assen, 2006; Fazey \& Fazey, 2001; Fisher et al., 2001; Walker \& Fraser, 2005). Thus, items pertinent to the ability to manage new situations, along with items relevant to the estimation of the extent of sensitivity towards others came to light. Finally, the scale was further developed on the basis of the outcomes of the interviews with the four postgraduate students, which included open-ended questions related to how they perceive autonomy in distance education and to which they consider as the main characteristics of autonomous students. The scale developed through this process comprised of 25 items, with responses on a five-point Likert-type scale (ranging from 1: strongly disagree, to 5: strongly agree). It also included five more items on demographic characteristics.

\section{Evaluation of the scale}

The scale was evaluated through a research in which two hundred and thirty-nine (239) HOU postgraduate students, following different course modules during the academic year 2015-2016, participated. The questionnaire was provided to the random sample of students during the counselling group sessions of each course module, under the instructions of the researcher, to ensure that all the necessary clarifications were provided.

The two final sub-scales as formulated with their items were: (a) the Personal Autonomy ScalePAS (Table 1) with 14 items, and (b) the Educational Autonomy Scale-EAS (Table 2) with 11 items.

\section{Table 1: Personal Autonomy Scale- PAS}

1 I make my own decision of the how and what of my studies.

2 I am aware of my abilities and limits in relation to my studies.

3 I can solely rely on me as far as my studies are concerned.

4 I know well which learning style suits me best.

5 I am positive towards the acquisition of new knowledge through alternative learning procedures.

6 I can manage any problem that may arise in my studies.

7 I seek alternative solutions when a difficult problem emerges in my studies.

8 I face the difficulties in my studies as a challenge.

9 I can easily adapt to difficult situations.

10 I am self-monitored throughout my studies.

11 I control my negative feelings.

12 I enjoy working on my own without feeling cut off from the rest.

13 I am not influenced by others' opinions and advice.

14 I look forward to my peers' acceptance/recognition. 


\section{Table 2: Educational Autonomy Scale- EAS}

1 I set realistic learning goals that meet my needs.

2 I choose the time and place of my studying according to my personal needs.

3 I plan in detail the steps I should take in order to pursue my goals.

4 I want to choose the content and method of my studies.

5 I want to choose the means and resources for my studying.

6 I am acquainted with the use of a variety of information resources.

7 I can self-evaluate my learning in total.

8 I want my teachers to let me act on my own.

9 I do not want to depend on my tutor.

10 I want my tutor to help me when it is absolutely necessary.

11 I want my tutor to take my personal experiences into account.

The results of the preliminary tests indicated problems in items 1, 5, 10, 13 and 14 for the personal autonomy scale and in items 9 and 11 for the educational autonomy scale respectively. More specifically, these questions were eliminated, as they did not contribute to a simple factor structure. To examine the factor structure of each dimension, a factor analysis of the remaining items was performed using the method of principal axis factoring with direct oblimin.

Regarding the personal autonomy scale, Bartlett's test of sphericity output, $\chi^{2}(36)=472.15$, $\mathrm{p}=.000$, resulted to the rejection of the hypothesis that the variables are independent from one another, while the KMO measure of sampling adequacy was .792 , which is a very satisfactory value, above the recommended value of .6 (Kaiser, 1974, as cited in Giossos, Koutsouba, \& Mavroidis, 2016). The discriminant of table $R$ was above the value of .00001 , suggesting that there was no multicollinearity problem. The scree plot of the factor analysis confirmed the following two factors: "self-awareness" and "autonomy in managing difficulties". The two factors and the variances of the items' loadings are displayed in Table 3.

Table 3: Factor loadings and factors in the personal autonomy scale

\begin{tabular}{lcc}
\hline & \multicolumn{2}{c}{ Factors } \\
& Autonomy in managing difficulties & Self-Awareness \\
\hline Item 9 & .871 & \\
Item 8 & .677 & \\
Item 7 & .431 & \\
Item 6 & .350 & \\
Item 11 & & .856 \\
Item 12 & & .547 \\
Item 4 & & .480 \\
Item 3 & $30.1 \%$ & $6.9 \%$ \\
Item 2 & \\
\hline Percentage of explained variance & \\
\hline Method of Factor extraction: Principal Axis Factoring & \\
Oblimin Method: Direct with Kaiser Normalization &
\end{tabular}

With regards to the internal consistency and reliability of these two factors, for the 'autonomy in managing difficulties' factor, Cronbach's alpha coefficient was .717 and for the 'self-awareness autonomy' factor, Cronbach's alpha coefficient was .658. These values are considered sufficient for psychometric scales. 
As far as the educational autonomy scale is concerned, Bartlett's Test of sphericity output, $x^{2}(36)=383.81, p=.000$, resulted in the rejection of the assumption that the variables are independent from one another, while the KMO measure of sampling adequacy was .775 which indicates the extraction of discrete factors. The discriminant of table $R$ was above the value of .00001 , which means that there was no multicollinearity problem. The scree plot of factor analysis confirmed the following two factors: "autonomy in action" and "autonomy in planning". The two factors and the variances of the items' loadings are displayed in Table 4.

Table 4: Factor loadings and factors in the educational autonomy scale

\begin{tabular}{lcc}
\hline & \multicolumn{2}{c}{ Factors } \\
& Autonomy in action & Autonomy in planning \\
\hline Item 5 & .756 & \\
Item 4 & .637 & \\
Item 8 & .582 & \\
Item 10 & .378 & \\
Item 6 & .352 & .675 \\
Item 1 & & .621 \\
Item 2 & .447 \\
Item 3 & .332 \\
Item 7 & $7 \%$ \\
\hline Percentage of explained variance & \\
\hline Method of Factor extraction: Principal Axis Factoring & \\
Oblimin Method: Direct with Kaiser Normalization &
\end{tabular}

As regards the internal consistency and reliability of the two factors, for the 'autonomy in action' factor the Cronbach's alpha coefficient was .668 and for the 'autonomy in planning' factor the respective value was .623. These values are considered sufficient for psychometric scales.

Finally, according to the results of the multivariable analysis of variance (MANOVA) no statistically significant gender differences were found for the following factors: (a) self-awareness $\left(F_{1,237}=3.114, p=.079\right)$, (b) action $\left(F_{1,237}=10.711, p=.203\right)$, and $(c)$ planning $\left(F_{1,237}=1.043\right.$, $p=.308)$. A statically significant difference was detected for the factor: 'autonomy in managing difficulties' $\left(F_{1,239}=10.711, p=.001\right)$.

Following the above, the final items of the Personal Autonomy Scale were seven: four under "Autonomy in managing difficulties", namely "I can solely manage any new problem that may emerge in my studies", "I seek alternative solutions when a difficult problem arises in my studies", "I face the difficulties in my studies as a challenge" and "I can easily adapt to difficult situations", and three under "Self-awareness autonomy", namely "I am aware of my abilities as well as my limits in relation to my studies", "I can solely rely on me throughout my studies" and "I know well which learning style suits me best". Regarding the Educational Autonomy Scale nine items were included in the final scale: four under "Autonomy in planning", namely "I set realistic goals that meet my needs", "I choose the time and place of my study according to my personal needs", "I plan in detail the steps to pursue my goals", and "I can evaluate my learning in total" and five under "Autonomy in action", namely "I want to choose the content and method of my studies", "I want to choose the means and resources for my studies", "I am acquainted with a variety of information resources", "I want my tutor to let me act on my own", and "I want my tutor to help me when it's absolutely necessary". The results of analysis leading to the final formulation of the scales are discussed in the following section. 


\section{Discussion}

The results of the exploratory factor analysis revealed two discrete factors for the personal autonomy scale, namely "self-awareness" and "managing difficulties", and two discrete factors for the educational autonomy scale, namely "autonomy in planning" and "autonomy in action". As far as the "self-awareness" factor is concerned, the statistical analysis of the responses of the sample of the present study, along with their high scores in the awareness of their limitations, clearly confirm the connection of this parameter with the control exerted over all the phases of the educational process and, consequently, with the autonomy of students. These results indicate that learners' autonomy has two distinguished dimensions, educational and psychological/personal. Furthermore, the existence of both dimensions of autonomy shows that these constitute important parameters in distance learning environments as suggested by theoreticians of distance education such as Moore, Peters, and Garrison.

The specific result tallies with the fact that distance education, which is closely linked with independent learning, is founded upon the concepts of "distance" and "autonomy" (Moore, 1972), at least from the learners" perspective (Garrison, 2003), and therefore presupposes greater autonomy on behalf of the learners. The studies by Giagli, Giaglis, and Koutsouba (2010), Fanariti and Spanaka (2010), and Fotiadou, Angelaki, and Mavroidis (2017), which were also conducted in HOU, as well as other studies that lead to similar conclusions (Güven \& Sünbül, 2007; Tassinari, 2012; Thanasoulas, 2000; White, 1995) confirm that self-awareness is a core parameter of the personal autonomy of learners.

Regarding the factor "managing difficulties", the respondents confirm the connection of autonomy with their ability to adapt to difficult situations and to seek alternative solutions consorted with their personal characteristics. The successful management of difficulties is a basic characteristic of the learners' personal autonomy dimension according to Moore's (1980) theory of transactional distance and also according to the preceding work of Wedemeyer (1977). Similar findings were observed in the studies of Leonard and Harvey (2007), Macaskill and Denovan (2011), Scott, Furnell, Murphy, and Goulder (2014), Zimmerman (2000) as well as by Furnborough (2012), where a large percentage of students could cope with all sorts of difficulties in a self-contained manner, simultaneously creating autonomy conditions.

On the contrary, the factor "interaction of students with their peers" does not seem to contribute to their autonomy (questions 13 and 14 of the personal autonomy scale were excluded from the statistical analysis, as unrelated to its evaluation parameters). Macaskill and Taylor's (2012) most recently constructed scale also doesn't include the interaction factor. However, in Bekker and van Assen's scale (2006) the relevant factor 'sensitivity towards the others' is fundamental for its construct. A plausible explanation of the above controversial finding might be that the majority of HOU students aim at a successful final assessment comprising of personal written assignments and exams, which has definitely an individualistic orientation. Therefore, they do not feel as much the need for interaction with their peers. As suggested in the study of Kassandrinou, Angelaki, and Mavroidis (2014), which was performed in the same educational environment, the limited face-to-face interaction and the lack of group assignments lead to an increased studentstudent transactional distance in the HOU. This is enhanced by the fact that postgraduate students of the HOU are accustomed to traditional face-to-face courses from their undergraduate studies, where they could interact more easily with their fellow students. It's highly probable that if group assignments were given to the students by the HOU and if peer-to-peer interaction was more encouraged, the interaction factor could have affected the structure of the scale examined here. 
Regarding the factor "autonomy in planning" the results of the present research indicated that educational autonomy, i.e. the extent to which the program itself creates the conditions for learning autonomy, is positively linked to the following parameters: (a) setting realistic goals that meet the students' needs, (b) choosing the time and place of their study, and (c) planning in details the intermediate goals and the conditions necessary for the completion of a learning project. Following this, the second factor, that of "autonomy in action", also confirms the positive correlation between the students' educational autonomy and the extent to which they choose the content, resources and methods of their learning, in addition to the opportunities of self-acting that their tutors offer. The aforementioned results are in agreement with those of other studies, which highlighted the learners' need to be actively involved in all the phases of the educational process (Fanariti \& Spanaka, 2010; Fotiadou, Angelaki, \& Mavroidis, 2017; Hurd, Beaven, \& Ortega, 2001; Tassinari, 2012; White, 1995).

As far as the examination of gender differences is concerned, the low score that women received in the personal autonomy scale, and more specifically in the 'managing difficulties' factor, could be attributable to the fact that women with youngsters or dependent elderly family members are facing difficulties in trying to play multiple, different and demanding roles, simultaneously satisfying a plethora of personal, social and professional obligations (Angelaki \& Mavroidis, 2013).

\section{Conclusions}

The aim of the present study was to develop a scale/questionnaire to measure the perceived autonomy of the postgraduate students involved in the distant education courses of the HOU. The study confirmed the existence of two discrete dimensions of autonomy, educational and psychological/personal autonomy. Furthermore, it revealed two discrete factors for the personal autonomy scale, namely "self-awareness" and "managing difficulties", and two discrete factors for the educational autonomy scale, namely "autonomy in planning" and "autonomy in action". The analysis performed led to a final overall scale with 16 items: seven under the Personal Autonomy Scale and nine under the Educational Autonomy Scale.

The notion of autonomy as a psychometric characteristic is determined by the cultural and educational conditions of its development context. For this reason, generalization of the developed scale outside this or very similar environments must be made with care, taking into account all relevant considerations. An exploratory factor analysis was performed in order to establish construct validity. Nevertheless, the factor structure of the two scales (personal and educational autonomy) should also be submitted to a confirmatory factor analysis (Thompson, 2004). To this end, a dedicated research study is recommended. It would be also interesting to conduct a similar research to HOU undergraduate students. Finally, given that autonomy is interdependent on the sociocultural and educational context of its development, this merits examination in other contexts of distance education.

\section{References}

1. Anderson, B. (2007). Independent Learning. In M.G. Moore (Ed), Handbook of Distance Education (pp.109-122). Mahwah, NJ: Lawrence Erlbaum Associates.

2. Andrade, M. S., \& Bunker, E. I. (2009). A model for self-regulated distance language learning. Distance Education, 30(1), 47-61.

3. Angelaki, C., \& Mavroidis, I. (2013). Communication and social presence: The impact on adult learner's emotions in distance learning. European Journal of Open Distance and e-Learning, 16(1), 78-93. 
4. Bekker, M. H. J., \& van Assen, M. A. L. M. (2006). A Short Form of the Autonomy Scale: Properties of the Autonomy - Connectedness Scale (ACS-30). Journal of personality assessment, 86(1), 51-60.

5. Biggs, M. J. G. (2006). Comparison of student perceptions of classroom instruction: Traditional, hybrid, and distance education. Turkish Online Journal of Distance EducationTOJDE, 7(2), 46-51.

6. Brockett, R. G., \& Hiemstra, R. (1991). Self-Direction in Adult Learning: Perspectives on Theory, Research and Practice. London and New York: Routledge.

7. Candy, P. C. (1991). Self-Direction for Lifelong Learning: A Comprehensive Guide to Theory and Practice. San-Francisco: Jossey-Bass.

8. Chene, A. (1983). The concept of autonomy in adult education: a philosophical discussion. Adult Education Quarterly, 34(1), 38-47.

9. Cronbach, L. J., \& Meehl, P. E. (1955). Construct validity in psychological tests. Psychological Bulletin, 52, 281-302.

10. Fanariti, M., \& Spanaka, A. (2010). Metacognition and Learner Autonomy during the preparation of written assignments. Open Education - The journal for Open and Distance Education and Educational Technology, 6(1-2), 138-151.

11. Fazey, D. M., \& Fazey, J. A. (2001). The potential for autonomy in learning: perceptions of competence, motivation and locus of control in first-year undergraduate students. Studies in Higher Education, 26(3), 345-361.

12. Field, L. (1989). An investigation into the structure, validity and reliability of Guglielmino's Self-Directed Learning Readiness Scale. Adult Education Quarterly, 39(3), 125-139.

13. Fisher, M., King, J., \& Tague, G. (2001). Self-directed Learning Readiness Scale. Nurse Education Today, 21, 516-525.

14. Fotiadou, A., Angelaki, C., \& Mavroidis, I. (2017). Learner Autonomy as a Factor of the Learning Process in Distance Education. European Journal of Open, Distance and e-Learning 20(1), 95-110. Retrieved from https://www.eurodl.org/materials/contrib/2017/Fotiadou\%20_et_al.pdf

15. Furnborough, C. (2012). Making the most of others: autonomous interdependence in adult beginner distance language learners. Distance Education, 33(1), 99-116.

16. Gall, M. Borg, W., \& Gall, J. (2014). Educational research. Basic Principles. (Karteroliotis, K). Cyprus: Broken Hill.

17. Garrison, D. R. (1997). Self-directed learning: Toward a comprehensive model. Adult Education Quarterly, 48(1), 15-31.

18. Garrison, R. (2000). Theoretical challenges for distance education in the $21^{\text {st }}$ century: A shift from structural to transactional issues. International Review of Research in Open and Distance Learning, 1(1), 1-17. Retrieved from http://www.irrodl.org/index.php/irrodl/article/viewFile/2/22

19. Garrison, D. R. (2003). Self-directed learning and distance education. In M.G. Moore, \& W.G. Anderson (Eds.), Handbook of distance education (pp.161-168). Mahwah, NJ: Lawrence Erlbaum Associates.

20. Giagli, S., Giaglis, G., \& Koutsouba, M. (2010). Learning Autonomy in Distance Education. Open Education - The Journal for Open and Distance Education and Educational Technology, 6(1-2), 92 105. 
21. Giossos, I., Koutsouba, M., \& Mavroidis, I. (2016). Development of an Instrument for Measuring Learner - Teacher Transactional Distance. American Journal of Distance Education, 30(2), 98-108. http://dx.doi.org/10.1080/08923647.2016.1156374

22. Guglielmino, L. M. (1977). Development of the Self-directed Learning Readiness Scale. Unpublished doctoral dissertation. Dissertation Abstracts International, 38, 64-67. University of Georgia.

23. Güven, Z., \& Sünbül, A. M. (2007). The Relation between the Learner's Autonomy Level and Their Learning Styles.

24. Hurd, S., Beaven, T., \& Ortega, A. (2001). Developing autonomy in distance language learning context: Issues and dilemmas for course writers. System, 29(3), 341-355.

25. Kaiser, J. M. (1974). An index of factorial simplicity. Psychometrika, 39(1), 31-36. doi:10.1007/BF02291575.

26. Kassandrinou, A., Angelaki, C., \& Mavroidis, I. (2014). Transactional Distance among Open University Students: How does it affect the learning process? European Journal of Open, Distance and E-Learning, 17(1), 26-42.

27. Keegan, D. (1996). Foundation of distance education (3 $3^{\text {rd }}$ ed.). London: Routledge

28. Lemone, K. (2005). Analyzing Cultural Influences on E-Learning transactional issues. Proceedings of the E-Learn: World Conference on E-Learning in Corporate, Government, Healthcare, and Higher Education, 2637-2644. Association for the Advancement of Computing in Education (AACE).

29. Leonard, N. H., \& Harvey, J. (2007). The trait of curiosity as a predictor of emotional intelligence. Journal of Applied Social Psychology, 37, 1545-1561.

30. Lionarakis, A. (2001): For which 'Distance Education' are we talking about? In A. Lionarakis (Ed.), Proceedings of the $1^{\text {st }}$ International Conference for Open \& Distance Education (Vol. A, pp.185194). Athens: Propompos.

31. Little, D. (1995). Learning as dialogue: The dependence of learner autonomy on teacher autonomy. System, 23(2), 175-181.

32. Little, D. (2004). Learner autonomy, teacher autonomy and the European Language Portfolio. Paper presented at the UNTELE, Université de Compiègne, 17-20 March 2004. Retrieved from http://www.utc.fr/ untele/2004ppt/handouts/little.pdf

33. Macaskill, A., \& Denovan, A. (2011). Developing autonomous learning in first-year university students using perspectives from positive psychology. Studies in Higher Education, 39(1), 124142. Retrieved from http://orcid.org/0000-0001-9972-8699

34. Macaskill, A., \& Taylor, E. (2010). The development of a brief measure of learner autonomy in university students. Studies in Higher Education, 35(3), 351-359.

35. Merriam, S. B., \& Caffarella, R. S. (1999). Learning in adulthood: A comprehensive guide (2 ${ }^{\text {nd }}$ ed.). San Francisco: Jossey-Bass.

36. Moore, M. G. (1972). Learner autonomy: The second dimension of independent learning. Convergence, 5(2), 76-88.

37. Moore, M. G. (1980). Independent study. In R. Boyd, \& J. Apps, (Eds.), Redefining the discipline of Adult Education, 5 (pp.16-31). San Francisco: Josei-Bass.

38. Moore, G. M. (1993). Theory of transactional distance. In D. Keegan (Ed.), Theoretical principles of distance education (pp.22-38). New York: Routledge. 
39. Moore, G. M. (2007). Theory of transactional distance. In M. G. Moore (Ed.), Handbook of distance Education (pp.89-103). Mahwah, NJ: Lawrence Erlbaum Associates.

40. Oxford, R. L. (2008). Hero with a thousand faces: Learning autonomy, learning strategies and learning tactics in independent language learning. In S. Hurd, \& T. Lewis (Eds.), Language learning strategies in independent settings (pp.41-63). Clevedon: Multilingual Matters.

41. Peters, O. (1998). Learning and teaching in distance education: Analyses and interpretations from an international perspective. London: Kogan Page.

42. Peters, O. (2000). Learning and teaching in distance education. Pedagogical analysis and interpretations in an international perspective. London and New York: Routledge.

43. Santos, R., \& Camara, M. (2010). Autonomy in Distance Learning: Reflections over the learner's role. Retrieved April 28, 2017, from http://www.abed.org.bt/congresso2010/cd/ing/252010174412.pdf

44. Sawilowsky, S. S. (2000). Psychometrics versus datametrics: Comment on Vacha-Haase's "reliability generalization" method and some EPM editorial policies. Educational and Psychological Measurement, 60(2), 157-173.

45. Scott, G. W., Furnell, J., Murphy, C. M., \& Goulder, R. (2014). Teacher and student perceptions of the development of learner autonomy: a case study in the biological sciences. Studies in Higher Education, 40(6), 945-956. doi: 10.1080./03075079.2013.842216

46. Sherril, C., \& O’Connor, J. (1999). Guidelines for improving adapted physical activity research. Adapted Physical Activity Quarterly, 16(1), 1-8.

47. Straka, G. A., \& Hinz, I. M. (1996). The original Self-Directed Learning Readiness Scale reconsidered. Conference proceedings $10^{\text {th }}$ International Self-Directed Learning Symposium, 6-10 March, 18. Florida: West Palm Beach.

48. Tassinari, M. G. (2012). Evaluating learner autonomy: A dynamic model with descriptors. Studies in Self-Access Learning Journal, 3(1), 24-40.

49. Thanasoulas, D. (2000). What is learner autonomy and how can it be fostered? The internet ETESL Journal, 6(11), 1-11.

50. Thomas, J., \& Nelson, J. (1996). Research methods in Physical Activity. Champaign IL: Human Kinetics.

51. Thompson, B. (2004). Exploratory and confirmatory factor analysis: Understanding concepts and applications. Washington, DC, US: American Psychological Association.

52. Walker, S. L., \& Fraser, B. J. (2005). Development and Validation of an Instrument for Assessing Distance Education Learning Environments in Higher Education: The Distance Education Learning Environments Survey (DELES). Learning Environments Research, 8(3), 289308. doi:10.1007/s10984-005-1568-3

53. Wedemeyer, C. (1977). Independent study. In A. S. Knowles (Ed.), The International Encyclopedia of Higher Education. Boston: Northeastern University.

54. White, C. (1995). Autonomy and Strategy use in distance foreign language learning: research findings. System, 23(2), 207-221.

55. Yun, J. K., \& Ulrich, D. A. (2002). Estimating measurement validity: A tutorial. Adapted Physical Activity Quarterly, 19, 32-47.

56. Zimmerman, B. J. (2000). Self - Efficacy: An Essential Motive to Learn. Contemporary Educational Psychology, 25, 82-91. 